\title{
A C-Band Geophysical Model Function for Determining Coastal Wind Speed Using Synthetic Aperture Radar
}

\author{
Lu Yiru ${ }^{1}$, Zhang Biao ${ }^{1}$, Perrie William ${ }^{2}$, Mouche Alexis ${ }^{3}$, Li Xiaofeng ${ }^{4}$, Wang He ${ }^{5}$
}

${ }_{1}^{1}$ Nanjing Univ Informat Sci \& Technol, Sch Marine Sci, Nanjing 210044, Jiangsu, Peoples R China.

2 Fisheries \& Oceans Canada, Bedford Inst Oceanog, Dartmouth, NS B2Y 4A2, Canada.

${ }^{3}$ Inst Francais Rech Exploitat Mer, Lab Oceanog Phys Spatiale, F-29280 Plouzane, France.

${ }^{4}$ NOAA, Global Sci \& Technol Inc, Natl Environm Satellite Data \& Informat Serv, College Pk, MD 20746 USA.

${ }^{5}$ State Ocean Adm, Natl Ocean Technol, Tianjin 300171, Peoples R China.

Corresponding author : Zhang Biao, email address : zhangbiao@nuist.edu.cn

lyr@nuist.edu.cn ; William.Perrie@dfo-mpo.gc.ca ; alexis.mouche@ifremer.fr ; xiaofeng.li@noaa.gov ; wanghe sio@126.com

\begin{abstract}
A new geophysical model function (GMF), called C_SARMOD2, has been developed to relate highresolution C-band normalized radar cross section (NRCS), acquired in VV polarization over the ocean, to the 10-m height wind speed. A total of 3078 RADARSAT-2 and Sentinel-1A VV-polarized synthetic aperture radar (SAR) images, acquired under different wind speed conditions, were collocated with in situ buoy measurements. The paired dataset was used to derive transfer functions and coefficients of C_SARMOD2, and then to validate the wind speed retrievals. The comparison between SAR-retrieved wind speeds and buoy measurements show almost no bias and a root mean square error of $1.84 \mathrm{~m} / \mathrm{s}$. Two representative quad-and dual-polarization SAR images, acquired from coastal regions, are used as case studies to examine C_SARMOD2 performances. The case study and statistical validation results suggest that the proposed C_SARMOD2 has the potential to measure coastal wind speeds at subkilometer resolutions. Although derived from low resolution NRCS measurements, this study also confirms the great robustness of CMOD5.N and recent CMOD7 when applied to SAR data. In addition, it shows that with the new generation of SAR satellite-borne sensors, it is no longer mandatory to rely on scatterometers in order to build a GMF, which will be used for SAR applications. Such an approach is particularly important in view of the upcoming RADARSAT Constellation Mission with new polarization configurations. Moreover, it also opens new perspectives on the derivation of GMFs in HH-polarization. However, these results also suggest that for coastal areas, the increase of the resolution to define the GMF is less important than adding other geophysical parameters to improve wind retrieval performance. This advocates for the necessity of revisiting the methodologies for ocean surface wind speed measurements in coastal areas.
\end{abstract}

Keywords : Coastal wind speed, geophysical model function (GMF), synthetic aperture radar (SAR) 


\section{INTRODUCTION}

Ocean surface wind fields play an important role in atmosphere-ocean interactions and the global water cycle. In coastal areas, ocean surface wind speeds and directions can dramatically change on a sub-kilometer scale. Accurate wind maps are crucial for coastal communities to prepare for windrelated hazards such as storm surges, flooding, and heavy rainfall. Moreover, coastal wind energy assessments also need access to high-resolution wind field information.

Satellite scatterometers are routinely used as operational tools for global oceanic wind vector measurements over large areas and with high temporal revisit frequencies. However, the applicability and usefulness of scatterometers are limited by their coarse spatial resolutions (usually about 12.5 or $25 \mathrm{~km}$ ). For operational wind products from the Advanced Scatterometer (ASCAT), at $25 \mathrm{~km}$ and 12.5 $\mathrm{km}$ wind vector cell spacing, data closer than $\sim 70 \mathrm{~km}$ (25 km products) or $\sim 35 \mathrm{~km}(12.5 \mathrm{~km}$ products $)$ to the coast are flagged because of land contamination [1]. A new wind product, denoted as "coastal product", was obtained from the ASCAT full-resolution backscatter data, resulting in good quality winds over the ocean, as close as $15-20 \mathrm{~km}$ to the shore [2]. Recently, ultra high-resolution (5.6 km) wind products have been derived from full-resolution ASCAT measurements [3]. However, the spatial resolution of scatterometer wind products is not sufficient to resolve the sub-kilometer variability of winds and provide measurements in coastal areas.

Compared to scatterometers, the high spatial resolution of SAR imagery makes it a very useful instrument for coastal wind field observations. For example, coastal katabatic wind patterns have been clearly detected by C-band RADARSAT-1 SAR, mirroring coastal mountain topography [4-5]. A recent investigation revealed the distinct patterns of wind direction change ocean surface temperature fronts using SAR-derived wind fields in coastal regions [6]. Quantitative retrievals of mesoscale coastal wind field are based on examination of both C-band European Remote Sensing (ERS) SAR image backscatter characteristics and its spectral properties [7]. Moreover, SAR-derived coastal wind 
speed validation has been completed with buoy observations and scanning LiDAR measurements [810]. From an application point of view, the operational coastal SAR wind field mapping system has demonstrated that it can help coastal communities to be prepared for wind-related hazards [11].

Coastal wind speed mapping is usually based on CMOD geophysical model functions (GMFs), such as CMOD_IFR2, CMOD4, CMOD5, and CMOD5.N [12-15]. Although derived from scatterometer VV-polarized measurements, they are widely used to retrieve ocean surface wind speeds from C-band SAR imagery [16-19]. CMOD5.N is considered to be the most reliable empirical GMF for SAR wind speed retrieval, with atmospheric stability correction implemented for Japanese coastal waters [20]. Previous investigation suggested that CMOD5 provided better wind speed estimation for hurricane force winds than CMOD4 [21].

In addition to these empirical GMFs, the spectral method [22] and a neighboring blocks algorithm [23] have also been developed to obtain wind speeds. Applications of the methods mentioned above have been carried out using advanced C-band Envisat ASAR, RADARSAT-1\&2, Sentinel-1A, and GF-3 SAR data. SAR wind speed validations show consistency between SAR retrievals and those from scatterometer and buoy measurements, as well as results from atmospheric model simulations [24-27]. Moreover, hybrid model functions that consist of CMOD GMFs and polarization ratio models are routinely utilized to retrieve ocean surface wind speeds using SAR imagery acquired at HH polarization [28-30].

For CMOD GMFs, ocean surface backscatter is related to radar incidence angle, wind speed and direction. Prior to wind speed retrieval, wind direction should be derived from SAR image itself, buoy or scatterometer measurements, or atmospheric model simulations. To avoid the effect of inaccurate wind direction on wind speed retrieval, an ocean vector winds retrieval algorithm is proposed by using C-band high-resolution quad-polarization SAR data [31]. The results of this method suggest smallscale wind speed variations $(6 \sim 15 \mathrm{~m} / \mathrm{s})$ in a $25 \times 25 \mathrm{~km}$ area.

Thanks to routine acquisitions by ENVISAT ASAR, there is a massive collection of ENVISAT 
ASAR measured backscatter data, collocated with ASCAT wind speed and direction data. This archive has been used for the first time to document the SAR NRCS sensitivity to ocean surface wind and radar incidence and azimuth angles, in both VV and $\mathrm{HH}$ polarizations [32]. However, this initial GMF derivation from SAR, denoted C-SARMOD, was not applied to any SAR wind speed retrieval and is limited to wind speeds up to $20 \mathrm{~m} / \mathrm{s}$.

Although conventional C-band CMOD GMFs can be used to estimate ocean surface wind speeds in open ocean regions, they may be inappropriate in coastal areas with specific and complex geophysical phenomena due to topography or shallow water. From a scientific point of view, the importance of this paper manifests in three aspects : (1) for the first time, we develop a GMF for highresolution $(100 \mathrm{~m}$ or $1 \mathrm{~km})$ wind speed retrieval from C-band SAR for coastal applications, by synthesizing backscatter measurements from two C-band SARs, such as RADARSAT-2 and Sentinel$1 \mathrm{~A}$, and by using only coastal buoy measurements, which opens new perspective on the derivation of GMF in HH-polarization but also for the forthcoming RCM SAR; and (2) we suggest that for coastal areas, the increase of the resolution to define the GMF is less important than adding other geophysical parameters to define the GMF; and (3) we show that other geophysical parameters than only wind speed and direction shoud be included in the GMF to improve the performances. Following the work proposed by Mouche and Chapron [32] to derive a GMF from SAR, the resulting GMF is simply denoted as C_SARMOD2. The feasibility of the proposed GMF for coastal wind mapping is illustrated using 2 case studies for validation and then statistically assessed. In particular, we directly compare wind speeds derived from the proposed GMF and other CMOD GMFs with in situ buoy observations. In Section II, we briefly describe the data set. The methodology to develop the C_SARMOD2 GMF is then presented in Section III. In Section IV, we show wind speed retrieval results and validation. Discussion and summary are given in Section V.

\section{DATA SET}


In this study, we used data from the C-band RADARSAT-2 (RS-2) quad-polarization $(\mathrm{HH}+\mathrm{HV}+\mathrm{VH}+\mathrm{VH})$ imaging mode and the dual-polarization $(\mathrm{VV}+\mathrm{VH})$ ScanSAR narrow imaging mode. A summary of the parameters for the RS-2 quad- and dual-polarization measurement modes, including incidence angles, spatial resolutions, swaths, and noise-equivalent sigma-zero (NESZ) values, is given in Table I. Moreover, images acquired by Sentinel-1A (S1A) SAR with the Interferometric Wide Swath (IW) mode were also acquired. The IW mode has the capability to observe the ocean surface with dual-polarization $(\mathrm{HH}+\mathrm{HV}$ or $\mathrm{VV}+\mathrm{VH})$ channels. Table II contains the major parameters for the S1A IW mode.

This study utilized 1696 RS-2 fine quad-polarization and 899 dual-polarization SAR images, from different geographic locations, that were collected between October 2008 and April 2013. We also obtained 483 S1A dual-polarization SAR images that were acquired with the IW imaging mode between January 2015 and November 2016.

\section{B. Buoy Data}

All RS-2 and S1A SAR images were collocated with 68 in situ National Data Buoy Center (NDBC) buoys located in the Gulf of Alaska and off the east and west coasts of the USA. The buoy-measured wind speeds and directions were averaged every 8 minutes. In order to be considered collocated, the buoy measurements and SAR images were required to be within a spatial interval of $10 \mathrm{~km}$ and a time interval of $30 \mathrm{~min}$. This approach resulted in 3078 collocated data pairs, which included winds ranging from 1 to $27 \mathrm{~m} / \mathrm{s}$ and 0 to $360^{\circ}$. Each pair included $\sigma_{0}$ for $\mathrm{VV}$ polarization, a radar incidence angle, and a buoy-measured wind speed and wind direction. This paired dataset was used to develop and validate the proposed C-band C_SARMOD2 GMF.

\section{Wind Speed Conversion and Distribution}


Since the anemometers on the NDBC buoys measure wind speeds at different heights $(3,4$, and 5 m) above the ocean surface, whereas the CMOD algorithms yield a proxy for the neutral wind speed at $10 \mathrm{~m}$, all buoy data were converted to the equivalent neutral winds at a height of $10 \mathrm{~m}$. To do so, we used a simple logarithmical wind profile equation, where wind speeds at a $10-\mathrm{m}$ height, $U(z)$, were defined as

$$
U(z)=U\left(z_{m}\right) \times \ln \left(z / z_{0}\right) / \ln \left(z_{m} / z_{0}\right)
$$

where $z_{0}$ is the roughness length (typical value of $1.52 \times 10^{-4}[33]$ ), $z$ is the height of $10 \mathrm{~m}, z_{m}$ is the anemometer height of the buoy, and $U\left(z_{m}\right)$ is the buoy-measured wind speed at height $z_{m}$. This expression was derived using a mixing length model that assumed neutral stability (i.e., it neglected the effects of differences in atmospheric stability), which may lead to errors when atmospheric conditions are atypical. Recent study showed that scatterometer wind measurements can be improved by using stress-equivalent reference winds [34]. It should be noted that the stress-equivalent wind correction method needs numerical weather prediction (NWP) model information for the humidity, sea surface temperature, and sea surface pressure to estimate the air mass density. In this study, we cannot calculate the air mass density and thus the stress-equivalent wind because buoys do not simultaneously provide these air-sea interface meteorological parameters.

For the collocated data set, we excluded the radar backscatter affected by rainfall, oil spills and biogenic slicks, coastal upwelling, and buoys without wind speed or wind direction observations. To remove SAR images that contain features not associated with the local wind, a filter was applied. The filter was developed to distinguish between homogeneous and heterogeneous SAR images and to retrieve ocean wave spectra and wind speeds [18-19]. This technique used tests involving the statistical properties of periodograms, as commonly used for spectral estimation. The details of this operation are described in [31]. After the application of this filter, 3044 collocated pairs were used to tune and validate the proposed C_SARMOD2 GMF. Histograms of the collocated buoy wind speeds and relative wind directions are shown in Fig.1. The histogram of collocated buoy wind speeds tends to 
exhibit a Weibull distribution, which is consistent with the distribution of global ocean surface wind speeds [35]. This may indicate that the collocated data were able to represent a range of weather situations, even though the collocated wind speed measurements were all below $27 \mathrm{~m} / \mathrm{s}$.

\section{Methodology}

We randomly selected 1522 collocated pairs for tuning of the C_SARMOD2 GMF. The remaining collocated pairs were used for statistical validation. These data were not sufficient to independently derive transfer functions by fitting the observed $\sigma_{0}$ from VV polarization to the buoy-measured ocean surface wind speed and wind direction. To overcome this problem, we introduced a practical approach to develop a GMF for the RS-2 and S1-1A data, based on CMOD5.

In CMOD5, the $\sigma_{0}$ for $\mathrm{VV}$ polarization is described by a nonlinear mapping function of the incidence angle, wind speed, and wind direction, which is given as

$$
z(v, \phi, \theta)=B_{0}^{p}(v, \theta)\left[1+B_{1}(v, \theta) \cos (\phi)+B_{2}(v, \theta) \cos (2 \phi)\right]
$$

where $B_{0}, B_{1}$, and $B_{2}$ are functions of the incidence angle, $\theta$, and the ocean surface wind speed, $v$, at a $10 \mathrm{~m}$ reference height. The relative wind direction, $\phi$, is the angle between the true wind direction and the radar observation direction. The transformation is defined as $z=\left(\sigma_{0}\right)^{p}$, with a constant $p$ value of 0.625. Throughout this paper, backscatter results will be presented for $\sigma_{0}$, rather than $z$. According to the CMOD5 model formulation, the isotropic term, $B_{0}$, the upwind/downwind amplitude, $B_{1}$, and the upwind/crosswind amplitude, $B_{2}$, are all functions of wind speed and incidence angle.

The transfer functions used to define $B_{0}$ and $B_{2}$ in C_SARMOD2 were adopted from CMOD5 for use in this study. We replaced the $x=(\theta-40) / 25$ definition from CMOD5 with the modified equation $x=(\theta-76) / 40$. The dependence of $B_{1}$ on wind speed and incidence angle follows the second-order polynomial function that was used in the XMOD2 [36], an X-band GMF:

$$
B_{1}=\sum_{j=0}^{2} \sum_{i=0}^{2} a_{i j} \theta^{i} v^{j}
$$

A stepwise regression was used in the tuning approach. First, it was assumed that the observed 
ocean surface backscatter $\sigma_{0}^{S A R}$ was only related to the wind speed and incidence angle, such that

$$
\sigma_{0}^{S A R} \approx B_{0}^{p}(v, \theta)
$$

The coefficients in $B_{0}$ were acquired by minimizing the cost function

$$
J_{\text {cost }}\left(B_{0}\right)=\sum_{i=1}^{N}\left(\sigma_{0 i}^{S A R}-B_{0}^{p}\left(v_{i}, \theta_{i}\right)\right)
$$

We neglected the difference in upwind and downwind effects on ocean surface backscatter, and only considered the difference in the effects of upwind and crosswind, so that $\sigma_{0}^{S A R}$ could be approximated as

$$
\sigma_{0}^{S A R} \approx B_{0}^{p}(v, \theta)\left(1+B_{2}(v, \theta) \cos (2 \phi)\right)
$$

Again, the transfer function coefficients in $B_{2}$ were determined using the nonlinear least squares fit method. As a result, we used the same approach to obtain the coefficients for the functions in $B_{1}$ when the difference of upwind and downwind on ocean surface backscatter in RS-2 and S1A SAR image was considered. The C_SARMOD2 model formulation and all 32 coefficients are described and defined in Appendix A. C_SARMOD2 should be applicable for C-band SAR data acquired with incidence angles between $20^{\circ}$ to $49^{\circ}$ and with VV polarization.

\section{RESULTS}

To assess the accuracy of the proposed C_SARMOD2, we carried out case study and statistical validations. We also compared the wind speeds derived from C_SARMOD2 with those from various CMOD GMFs.

\section{A. Case Validation}

We applied the proposed C_SARMOD2 to two RS-2 SAR images acquired with quad- and dualpolarization imaging modes. Fig. 2(a) shows a VV-polarized RS-2 SAR image acquired with the fine quad-polarization mode on May 24, 2012, at 13:53 Coordinate Universal Time (UTC). This SAR image was collocated with NDBC buoy \#46047 (32²3'54" N 119²9'54" W), off the west coast of the USA. The buoy-measured wind speed at $10 \mathrm{~m}$ height was $12.8 \mathrm{~m} / \mathrm{s}$. Fig. $2 \mathrm{~b}$ shows the NRCS along the 
transect (indicated in Fig. 2(a)) versus the radar incidence angle. The NRCS variation is about $4.5 \mathrm{~dB}$ as the incidence angle ranges between $43.9^{\circ}$ and $45^{\circ}$, which corresponds to the light and dark stripes associated with the atmospheric gravity wave in the Fig. 2a. Fig. 2(c) illustrates a time series of buoymeasured wind speeds over one hour around the SAR acquisition time. This shows the drastic variation in wind speed caused by the passage of an atmospheric gravity wave. Indeed, the buoy measures a wind speed oscillation as a function of time during the time frame considered. From the in-situ point of view, this temporal fluctuation is consistent with the spatial variation of the NRCS as observed in the SAR image at a given time.

For this particular case and at each SAR image pixel, we used the same buoy-measured wind direction as input for the wind speed retrieval. Subsequently, various GMFs and the proposed C_SARMOD2 were used to retrieve wind speeds. Fig. 3(f) shows the wind speeds derived from C_SARMOD2. It is worth mentioning that the spatial resolution is $100 \mathrm{~m}$ for the retrieved wind speeds. As obtained, wind speeds vary from 5 to $20 \mathrm{~m} / \mathrm{s}$ on a $100 \mathrm{~m}$ resolution scale over this $25 \mathrm{~km}$ x $25 \mathrm{~km}$ area. Wind speeds calculated by six different GMFs, along with the buoy observations, are summarized in Table III. The wind speed inferred by C_SARMOD2 at buoy \#46047 was $12.5 \mathrm{~m} / \mathrm{s}$. The wind speed difference between the C_SARMOD2 retrieval and the buoy observation was therefore $0.3 \mathrm{~m} / \mathrm{s}$. Across all buoy comparisons, C_SARMOD2 achieved a smaller wind speed bias than the other GMFs that were tested. SAR-retrieved wind speeds from the other GMFs are also shown in Figs. 3(a)-3(e). They all reveal significant wind speed variations across the small $25 \mathrm{~km}$ x $25 \mathrm{~km}$ area. However, compared to buoy measurement, wind speeds derived from these GMFs are underestimated, as shown in Table III. Consequently, for this case, the proposed C_SARMOD2 provides more accurate wind speeds than other GMFs.

We also examined the proposed C_SARMOD2 using a wide swath SAR image. Fig. 4 shows a RS-2 SAR image acquired from the dual-polarization ScanSAR imaging mode on January 3, 2010, at 22:20 UTC. There are five NDBC buoys off the east coast of the USA in this SAR imaging area, which 
are listed in the Table III. The wind speeds from these five buoys ranged from 6 to $15 \mathrm{~m} / \mathrm{s}$. Fig. 5 clearly shows a front near buoy \#44037, with high ocean backscatter north of the buoy and low ocean backscatter to the south. There is also a very low backscatter/wind region far from the front. For this case, the input wind directions for the SAR wind speed retrievals were provided by the National Centers for Environmental Prediction (NCEP) Climate Forecast System (CFS) reanalysis wind field data (apdrc.soest.hawaii.edu/dods/public_data/CFSv2). The temporal and spatial resolutions of the CFS reanalysis data are 1 hour and $56 \mathrm{~km}$, respectively. Although, certainly not high enough resolution to capture all the wind variability in the coastal area, this is the only source of wind data available for this study. We first resampled the SAR image from the original $25 \mathrm{~m}$ pixel spacing to $1 \mathrm{~km}$, and then we linearly interpolated wind directions from the CFS reanalysis data to each image pixel. The time interval between SAR image acquisition and the CFS data is 20 minutes. Fig. 5(f) shows the SARderived wind speeds with $1 \mathrm{~km}$ spatial resolution, using the proposed C_SARMOD2 GMF, with the CFS wind directions overlaid. The retrieved wind speeds ranged from 3 to $20 \mathrm{~m} / \mathrm{s}$. Again, the wind speed map distinctly shows the wind front that appears in the SAR image. The frontal zone is marked by obvious changes in wind directions. Figs. 5(a) to 5(e) also include wind speed maps derived from the four CMOD GMFs used for the comparisons. Underestimates in wind speeds are apparent in both near and far ranges for CMOD4 and CMOD_IFR2. In the high wind speed regions, the wind speeds derived by CMOD5 and CMOD5.N are better than those from CMOD4 and CMOD_IFR2. As shown in the Fig. 5, we find that C_SARMOD2 provides more reasonable wind speed distribution maps than the other CMOD GMFs. Table III summarizes the wind speed comparisons between SAR retrievals and the various GMF retrievals, as well as buoy measurements. On average, the C_SARMOD2derived wind speeds were closer to the buoy data than the other CMOD GMFs. It is notable that for this particular case, all GMFs underestimated the wind speeds. The underestimation is possibly caused by the inaccurate NRCS calibration, wind direction and other factors. To our knowledge, the wind speed retrieval errors are possibly related to NRCS calibration, wind direction and other effects. In 
[24], the effect of absolute NRCS accuracy on SAR wind speed retrieval was analyzed by using numerical simulation, suggesting a $0.5 \mathrm{~dB}$ calibration error will induce small impact $(<0.5 \mathrm{~m} / \mathrm{s})$ on SAR wind retrieval for moderate incidence angles and low to moderate wind speeds. For scatterometer, a new calibration technique termed cone metrics succeeds at establishing the linear and nonlinear corrections necessary to homogenize the ASCAT and ERS C-band records down to $0.05 \mathrm{~dB}$ [37]. For SAR, such as RADARSAT, the absolute radiometric error is $0.2 \mathrm{~dB}$ and the relative radiometric error within an image is $0.2 \mathrm{~dB}$ [38-40]. The NRCS is dependent on wind direction and therefore, uncertainties in wind direction can lead to error in wind speed. Assuming an uncertainty in wind direction of $\pm 10^{\circ}$, the effect of wind direction on wind speed retrieval was assessed for incidence angles of $20^{\circ}, 35^{\circ}$, and $50^{\circ}$ and wind speed ranging between $2 \mathrm{~m} / \mathrm{s}$ and $30 \mathrm{~m} / \mathrm{s}$, showing that inaccurate wind direction will cause wind speed error $(\sim 1 \mathrm{~m} / \mathrm{s})$ for low and moderate wind speeds [41]. Moreover, a wind direction bias toward crosswind will produce an overestimation of wind speeds, and a bias toward upwind or downwind will induce underestimation in the wind speeds [42].

In addition to NRCS calibration and wind direction, the wind speed underestimations in coast areas are also possibly caused by other factors. Previous research has suggested that short-fetch areas displayed a typical underestimation in ASCAT wind speed of 0.2-0.3 m/s [15]. Moreover, past study also reported that the large negative in the SAR-derived offshore winds is possibly related to the short fetches from the coastline [20]. This seems consistent with our analysis. Indeed, in addition to wind speed, the fetch distance and duration of wind blowing over the sea surface can also change the sea surface roughness, especially in coastal waters. Other parameters, such as wind direction, planetary boundary layer (PBL) height and air mass density also change with distance from the coast. For fetchlimited seas, the waves are not in equilibrium with the near-surface wind speed. Fig. 5(f) is a typical offshore wind case. The bias between C_SARMOD2 retrievals and buoy measurements are $-1.04 \mathrm{~m} / \mathrm{s}$ and $-0.37 \mathrm{~m} / \mathrm{s}$ for buoys \#44037 and \#44005, and are $-1.99 \mathrm{~m} / \mathrm{s},-2.17 \mathrm{~m} / \mathrm{s}$ and $-1.70 \mathrm{~m} / \mathrm{s}$ for buoys \#44032, \#44034 and \#44027. Compared to buoys \#44037 and \#44005, buoys \#44032, \#44034 and 
\#44027 are closer to the shore, and thus we expect the fetch effect on the the latter buoys to be stronger than the former, leading to a larger negative bias. An additional effect is the reduction in roughness over water compared to over land, causing offshore winds to speed up as they go from land to open ocean, but this mechanism occurs mostly within about $30 \mathrm{~km}$ of the shoreline [43-44]. This case study suggests that the impact of fetch on NRCS could be larger at high resolution as observed by SAR than at lower resolution as observed by scatterometers.

\section{B. Statistical Validation}

Fig. 6 is a set of plots of the statistical comparisons between SAR-retrieved wind speeds from six different GMFs and buoy measurements. It should be noted that the 1452 SAR images for wind speed statistical validation were all acquired in coastal area. The RMSEs for SAR wind speeds calculated by CMOD4, CMOD5, CMOD_IFR2 and C_SARMOD were all larger than $1.9 \mathrm{~m} / \mathrm{s}$. The wind speeds generated by C_SARMOD2 yielded the best match with the buoy observations: Bias and RMSE are 0.04 and $1.84 \mathrm{~m} / \mathrm{s}$, respectively and the scatter index is $20.92 \%$. Moreover, we found that the wind speed retrieval accuracy of CMOD5.N is close to that of C_SARMOD2. Fig. 6(f) shows an larger scatter when wind speeds are larger than $15 \mathrm{~m} / \mathrm{s}$. Since buoy-measured wind directions are used as the inputs of C_SARMOD2, the reason for this increasing scatter could be associated with the NRCS error. To prove this speculation, we compute the error in wind speed assuming an accuracy of $\pm 0.5 \mathrm{~dB}$. The results are shown in Fig.7. It is shown that for moderate incidence angles, $0.5 \mathrm{~dB}$ NRCS error could induce $2 \mathrm{~m} / \mathrm{s}$ error in wind speeds when wind speeds are larger than $15 \mathrm{~m} / \mathrm{s}$. To further examine the performance of CMOD5.N and C_SARMOD2, we analyzed the wind speed retrieval errors (Bias and RMSE) in different wind speed bins and radar incidence angle bins, as illustrated in Fig. 8. It is shown that the Bias and RMSE of C_SARMOD2 are smaller than those of CMOD5.N for high wind speed bins, indicating that C_SARMOD2 has potential to more accurately derive the wind speeds than CMOD5.N in coastal regions. We evaluated the wind speed mapping capability of the recently developed GMF CMOD7 [45] using the same dataset. The resulting bias and RMSE are $-0.59 \mathrm{~m} / \mathrm{s}$ and 
$1.93 \mathrm{~m} / \mathrm{s}$, as shown in Fig. 9. In terms of RMSE, the C_SARMOD2 is close to CMOD7. We also examined the wind speed retrieval errors in different incidence angle and wind speed bins for C_SARMOD2 and CMOD7. The results (not shown here) are similar with those illustrated in the Fig.8.

\section{Discussion and Summary}

High-resolution and high-accuracy coastal wind information is important for many applications such as offshore wind energy assessment and planning, ship traffic, and harbor management. However, neither wind measurements from sparse networks of buoys nor low-resolution satellite microwave radiometer or scatterometer wind measurements can resolve the details of sub-kilometer scale wind variability, particularly close to the coasts. Conventional CMOD GMFs can be used to infer ocean surface wind speeds from C-band SAR images, but several potential problems could affect the accuracy of their results in coastal areas. Indeed, most of the existing CMOD GMFs are based on lowto-medium resolution scatterometer measurements in the open ocean. SAR has high spatial resolution and is able to map fine-scale wind features as close as several hundreds of meters from the coastline. Taking benefit of a large number of C-band SAR data acquired in coastal regions and collocated with buoy observations, we develop a GMF for high-resolution NRCS. This allows wind mapping and investigation of small-scale wind variations in coastal areas.

In this paper, for the first time, we build a C-band GMF, called C_SARMOD2, for SAR coastal high-resolution (100 m or $1 \mathrm{~km})$ wind speed retrieval, using backscatter measurements from two different C-band SARs: RS-2 and S-1A. The isotropic and the upwind/crosswind amplitude transfer functions of CMOD5 are adopted for C_SARMOD2, whereas a second-order polynomial function is chosen for the upwind/downwind amplitude. The 1522 data pairs used to tune the C_SARMOD2 model are not comparable with those used to tune existing CMOD GMFs, so a stepwise regression method is used to tune the coefficients. This significantly reduces the number of coefficients determined by a single process, and yields a stable result. 
To validate the results of the proposed C_SARMOD2, we used both quad- and dual-polarized SAR images to retrieve wind speeds in coastal areas. These speeds were compared with buoy measurements. C_SARMOD2 shows smaller bias than the existing CMOD GMFs that were used as comparisons, whether the SAR image was acquired with quad- or dual-polarized imaging mode. The retrieved coastal wind speed maps reflected differential wind speeds on a sub-kilometer scale. We also used an independent dataset to make a statistical comparison between wind speed retrievals with C_SARMOD2 and buoy measurements. The results showed that the bias and RMSE are $-0.04 \mathrm{~m} / \mathrm{s}$ and $1.84 \mathrm{~m} / \mathrm{s}$, respectively. These positive results suggest that the proposed C_SARMOD2 GMF could represent an improvement in wind speed derivation in coastal areas. The errors existing in the retrieved wind speeds are associated with the NRCS calibration, wind direction and other factors. It should be noted that the proposed C_SARMOD2 derived using buoy winds without taking the air density into account, which will be included in a future study. We must also underline the remarkable robustness of CMOD5.N and CMOD7, although they have been derived with low-to-medium resolution scatterometer measurements in the open ocean. More interestingly, we also found that offshore wind speeds were underestimated whether using existing CMOD GMFs or C_SARMOD2. As a matter of fact, this suggests that for wind measurements in coastal areas, the definition of a GMF including extra geophysical parameters would be certainly a significant improvement.

Compared to wind measurements in the open ocean, many factors can also affect sea surface roughness, such as upwelling, or fetch. Moreover, because the signal is analyzed at very high resolution, localized phenomena such as solitons, wave-current interactions, and biologenic filaments will more significantly impact the NRCS. This will influence coastal wind maping. In this study, these effects on radar backscatter have not included in the proposed C_SARMOD2. The study of such effects requires the acquisition of a sufficient number of SAR images together with ancillary data allowing both the qualification and the quantification of these effects. This will be the subject of future work. More practically, it is very promising that the GMF to be used for ocean surface wind retrieval can 
be derived without using scatterometer data. Indeed, this work will certainly benefit from more data collected by other C-band SAR satellites such as GF-3 and Sentinel-1 B . Accordingly, this also opens new perspectives that may be following in the derivation of a new GMF for HH polarization. Finally, the forthcoming launch of the RADARSAT Constellation Mission (RCM) with new polarization configurations and opportunities may adopt the same approach to derive adapted GMFs.

Acknowledgments: The authors would also like to thank the European Space Agency for providing Sentinel-1A data and the Canadian Space Agency for providing RADARSAT-2 data. This work was supported by the National Key R\&D Program of China [Grant 2016YFC1401001], the National Science Foundation of China for Outstanding Young Scientist [Grant 41622604], the Excellent Youth Science Foundation of Jiangsu Province [Grant BK2016090], the International Cooperation, CAS, Chinese-Foregin Cooperation in Key Project [Grant 133337KYSB], and the Data Utilization Application Plan [DUAP] of the Canadian Space Agency. The NOAA buoy data is downloaded from http://www.ndbc.noaa.gov/. The views, opinions, and findings contained in this paper are those of the authors and should not be construed as an official NOAA or U.S. government position, policy, or decision.

\section{Appendix A: C_SARMOD2 Model Formulation and Coefficients}

The final form of the C_SARMOD2 is

$$
z(v, \phi, \theta)=B_{0}^{p}(v, \theta)\left(1+B_{1}(v, \theta) \cos (\phi)+B_{2}(v, \theta) \cos (2 \phi)\right),
$$

where $z=\left(\sigma_{V V}^{0}\right)^{p}, p$ is a constant with a value of $0.625, B_{0}, B_{1}$, and $B_{2}$ are functions of the sea surface wind speeds and the incidence angle, $\theta$, or alternatively, $x=(\theta-76) / 40$. The form of $B_{0}$ is defined as

$$
B_{0}=10^{a_{0}+a_{1}} f\left(a_{2} v, s_{0}\right)^{\gamma},
$$

where

$$
f\left(s, s_{0}\right)=\left\{\begin{array}{c}
\left(s_{0}\right)^{\alpha} g\left(s_{0}\right), s<s_{0} \\
g(s), s \geq s_{0} \\
16
\end{array}\right.
$$


in which

$$
g(s)=1 /(1+\exp (-s)), \text { and } \alpha=s_{0}\left(1-g\left(s_{0}\right)\right)
$$

The $a_{0}, a_{1}, a_{2}, \gamma$ and $s_{0}$ terms are functions that depend on incidence angle:

$$
\begin{gathered}
a_{0}=c_{1}+c_{2} x+c_{3} x^{2}+c_{4} x^{3} \\
a_{1}=c_{5}+c_{6} x \\
a_{2}=c_{7}+c_{8} x \\
\gamma=c_{9}+c_{10} x+c_{11} x^{2} \\
s_{0}=c_{12}+c_{13} x .
\end{gathered}
$$

The $B_{1}$ term is defined as

$$
B_{1}=\left(c_{14}+c_{15} x+c_{16} x^{2}\right)+\left(c_{17}+c_{18} x+c_{19} x^{2}\right) v+\left(c_{20}+c_{21} x+c_{22} x^{2}\right) v^{2}
$$

The $B_{2}$ term is the same as in CMOD5, i.e.,

$$
B_{2}=\left(-d_{1}+d_{2} v_{2}\right) \exp \left(-v_{2}\right) \text {, }
$$

where $v_{2}$ is given by

$$
v_{2}=\left\{\begin{array}{c}
a+b(y-1)^{n}, y<y_{0}, y=\frac{v+v_{0}}{v_{0}}, \\
y, y \geq y_{0}
\end{array}\right.
$$

where

$$
\begin{gathered}
y_{0}=c_{19}, n=c_{20} \\
a=y_{0}-\left(y_{0}-1\right) / n, b=1 /\left[n\left(y_{0}-1\right)^{n-1}\right] .
\end{gathered}
$$

The functions $v_{0}, d$, and $d_{2}$ depend on incidence angle only:

$$
\begin{gathered}
v_{0}=c_{21}+c_{22} x+c_{23} x^{2} \\
d_{1}=c_{24}+c_{25} x+c_{26} x^{2} \\
d_{2}=c_{27}+c_{28} x .
\end{gathered}
$$

The values of all coefficients are presented in Table A.

Table A

\begin{tabular}{lll}
\hline \hline Function & Coefficients & Value
\end{tabular}




\begin{tabular}{|c|c|c|}
\hline \multirow[t]{13}{*}{$B_{0}$} & $c_{1}$ & -2.8780622366 \\
\hline & $c_{2}$ & -1.5077532007 \\
\hline & $c_{3}$ & 4.1260323346 \\
\hline & $c_{4}$ & -1.5711509362 \\
\hline & $c_{5}$ & 0.0997839563 \\
\hline & $c_{6}$ & 0.1943151071 \\
\hline & $c_{7}$ & 0.0853019437 \\
\hline & $c_{8}$ & 0.0423670106 \\
\hline & $c_{9}$ & -2.1945846847 \\
\hline & $c_{10}$ & -7.2757087820 \\
\hline & $c_{11}$ & 16.7457729177 \\
\hline & $c_{12}$ & -5.0000000000 \\
\hline & $c_{13}$ & 0.0000000000 \\
\hline \multirow[t]{9}{*}{$B_{1}$} & $c_{14}$ & 1.6262333825 \\
\hline & $c_{15}$ & 3.2035061281 \\
\hline & $c_{16}$ & 1.4814737802 \\
\hline & $c_{17}$ & -0.2925732996 \\
\hline & $c_{18}$ & -0.6027286857 \\
\hline & $c_{19}$ & -0.2876782583 \\
\hline & $c_{20}$ & 0.0075631819 \\
\hline & $c_{21}$ & 0.0162863438 \\
\hline & $c_{22}$ & 0.0079465051 \\
\hline \multirow[t]{3}{*}{$B_{2}$} & $c_{23}$ & 0.6570442777 \\
\hline & $c_{24}$ & 0.8104630338 \\
\hline & $c_{25}$ & -0.8299069674 \\
\hline
\end{tabular}




\begin{tabular}{l|c|c}
\hline & $c_{26}$ & -1.1085577699 \\
\hline & $c_{27}$ & 9.8518085953 \\
\hline & $c_{28}$ & 16.5848227251 \\
\hline & $c_{29}$ & 19.6328229062 \\
\hline & $c_{30}$ & 6.0612983104 \\
\hline & $c_{31}$ & 6.4694645110 \\
\hline \hline
\end{tabular}

\section{References}

[1] EUMETSAT, ASCAT Products Guide, 2011. [Online]. Available: http://www.eumetsat.int

[2] A. Verhoef, M. Portabella, and A. Stoffelen, "High-resolution ASCAT scatterometer winds near the coast," IEEE Trans. Geosci. Remote Sens., vol. 50, no. 7, pp. 2481-2487, 2012.

[3] J. Vogelzang and A. Stoffelen, "ASCAT Ultrahigh-Resolution Wind Products on Optimized Grids," IEEE J. Sel. Topics. Appl. Earth. Observ. Remote Sens., vol. 10, no. 5, pp. 2332-2339, 2017.

[4] W. Alpers, Ulrike Pahl, and G. Gross, "Katabatic wind fields in coastal areas studied by ERS-1 synthetic aperture radar imagery and numerical modeling," J. Geophys. Res., vol. 103, no. 4, pp. 7875-7886, 1998.

[5] X. Li, W. Zheng, W. G. Pichel, C.-Z. Zou, and P. Clemente-Colo'n, "Coastal katabatic winds imaged by SAR," Geophys. Res. Lett., vol. 34, L03804, 2007.

[6] T.-S. Kim, K.-A. Park, X. Li, A. Mouche, B. Chapron, M. Lee, “Observation of wind direction change on the sea surface temperature front using high-resolution full polarimetric SAR data," IEEE J. Sel. Topics. Appl. Earth. Observ. Remote Sens., vol. 10, no. 6, pp. 2599-2607, 2017.

[7] E. Korsbakken, J. A. Johannessen, and O. M. Johannessen, “Coastal wind field retrievals from ERS synthetic aperture radar images," J. Geophys. Res., vol. 103, no. 4, pp. 7857-7874, 1998.

[8] C. M. Fisher, G. S. Young, N. S. Winstead, J. D. Haqq-Misra, "Comparison of synthetic aperture 
radar-derived wind speeds with buoy wind speeds along the mountainous alaskan coast," J. Appl. Meteor. Climatol., vol. 47, pp. 1365-1376, 2008.

[9] T.-S. Kim, K.-A. Park, X. Li, and S. Hong, "SAR-derived wind fields at the coastal region in the East/Japan Sea and relation to coastal upwelling," Int. J. Remtoe Sens., vol. 35, pp. 3947-3965, 2013.

[10] T. Ahsbahs, M. Badger, I. Karagali, and X. Guo, "Validation of Sentinel-1A SAR coastal wind speeds against scanning LiDAR," Remote Sens., vol. 9, no. 552, 2017.

[11] F. M. Monaldo, C. R. Jackon, W. G. Pichel, and X. Li, "A weather eye on coastal winds," EOS., vol. 96, doi:10.1029/2015EO034581, 2015.

[12] Y. Quilfen, B. Chapron, T. Elfouhaily, K. Katsaros, and J. Tournadre, “Observation of tropical cyclones by high-resolution scatterometry," J. Geophys. Res., vol. 103, no. C4, pp. 7767-7786, Apr. 1998.

[13] A. Stoffelen and D. Anderson, "Scatterometer data interpretation: Estimation and validation of the transfer function CMOD4," J. Geophys. Res., vol. 102, no. C3, pp. 5767-5780, Mar. 1997.

[14] H. Hersbach, A. Stoffelen, and S. de Haan, "An improved C-band scatterometer ocean geophysical model function: CMOD5," J. Geophys. Res., vol. 112, C03006, 2007.

[15] H. Hersbach, "Comparison of C-band scatterometer CMOD5.N equivalent neutral winds with ECMWF,”J. Atmos. Ocean. Technol., vol. 27, no. 4, pp. 721-736, Apr. 2010.

[16] S. Lehner, J. Horstmann, W. Koch, and W. Rosenthal, "Mesoscale wind measurements using recalibrated ERS SAR images,” J. Geophys. Res., vol. 103, no. C4, pp. 7847-7856, Apr. 1998.

[17] S. Lehner, J. Schulz-Stellenfleth, B. Schattler, H. Breit, and J. Horstmann, "Wind and wave measurements using complex ERS SAR wave mode data," IEEE Trans. Geosci. Remote Sens., vol. 38, no. 5, pp. 2246-2257, Sep. 2000.

[18] J. Horstmann, H. Schiller, J. Schulz-Stellenfleth, and S. Lehner, "Global wind speed retrieval from SAR," IEEE Trans. Geosci. Remote Sens., vol. 41, no.10, pp. 2277-2286, Oct. 2003. 
[19] J. Horstmann and W. Koch, "Measurement of ocean surface winds using synthetic aperture radars," IEEE J. Ocean. Eng., vol. 30, no. 3, pp. 508-515, Jul. 2005.

[20] Y. Takeyama, T. Ohsawa, K. Kozai, and C. B. Hasager, "Comparison of geophysical model functions for SAR wind speed retrieval in Japanese coastal waters," Remote Sens., vol. 5, pp. 19561973, 2013.

[21] J. Horstmann, D. R. Thompson, F. Monaldo, S. Iris, and H. C. Graber, "Can synthetic aperture radars be used to estimate hurricane force winds?," Geophys. Res. Lett., vol. 32, L22801, 2005.

[22] P. W. Vachon, H. E. Krogstad, and J. S. Paterson, “Airborne and spaceborne synthetic aperture radar observations of ocean waves," Atmos-Ocean., vol. 32, pp. 83-112, 1994.

[23] Y. He, W. Perrie, Q. Zou, and P. W. Vachon, "A new wind vector algorithm for C-band SAR," IEEE Trans. Geosci. Remote Sens., vol. 43, no. 7, pp. 1453-1458, Jul. 2005.

[24] X. Yang, X. Li, W. G. Pichel, and Z. Li, "Comparison of ocean surface winds from ENVISAT ASAR, MetOp ASCAT scatterometer, buoy meansurements and NOGAPS model," IEEE Trans. Geosci. Remote Sens., vol. 49, no. 12, pp. 4743-4750, Dec. 2011.

[25] X. Yang, X. Li, W. G. Pichel, and Z. Li, "Comparison of ocean-surface winds retrieved from QuikSCAT scatterometer and RADARSAT-1 SAR in offshore waters of the US west coast," IEEE Geosci. Remtoe Sens. Lett., vol. 8, no. 1, pp. 163-167, Jan. 2011.

[26] F. Monaldo, C. Jackson, X. Li, and W. G. Pichel, "Preliminary evaluation of Sentinel-1A wind speed retrievals," IEEE J. Sel. Topics. Appl. Earth. Observ. Remote Sens., vol. 9, no. 6, pp. 26382642, 2016.

[27] H. Wang, J. Yang, A. Mouche, W. Shao, J. Zhu, L. Ren, and C. Xie, "GF-3 SAR ocean wind retrieval: The first view and preliminary assessment," Remote Sens., vol. 9, no. 694, doi:10.3390/rs9070694.

[28] B. Zhang, W. Perrie, and Y. He, "Wind speed retrieval from RADARSAT-2 quad-polarization images using a new polarization ratio model," J. Geophys. Res., vol. 116, no. C8, p. C08008, 2011, 
doi:10.1029/2010JC006522.

[29] C. C. Wackerman, P. Clemente-Colon, W. G. Pichel, and X. Li, "A two-scale model to predict Cband VV and HH normalized radar cross section values over the ocean," Can. J. Remote Sens., vol. 28, no. 3, pp. 367-384, 2002.

[30] G. Liu, X. Yang, X. Li, B. Zhang, W. G. Pichel, Z. Li, and X. Zhou, “A systematic comparison of the effect of polarization ratio models on sea surface wind retrieval from C-band synthetic aperture radar," IEEE J. Sel. Topics. Appl. Earth. Observ. Remote Sens., vol. 6, pp. 1100-1108, doi:10.1109/JSTARS. 2013.2242848.

[31] B. Zhang, W. Perrie, P. W. Vachon, X. Li, W. G. Pichel, J. Guo, and Y. He,“Ocean vector winds retrieval from C-band fully polarimetric SAR measurements," IEEE Trans. Geosci. Remote Sens., vol. 50, no. 11, pp. 4252-4261, 2012.

[32] A. Mouche, and B. Chapron, "Global C-band Envisat, RADARSAT-2 and Sentinel-1 SAR measurements in copolarization and cross-polarization," J. Geophys. Res., Oceans, 120, 71957207, 2015.

[33] J. P. Peixoto and A. H. Oort, Physics of Climate. Woodbury, NY, USA: Amer. Inst. Phys., 1992.

[34] J. de Kloe., A. Stoffelen, and A. Verhoef, "Improved use of scatterometer measurements by using stress-equivalent reference winds," IEEE J. Sel. Topics. Appl. Earth. Observ. Remote Sens., vol. 10, pp. 2340-2347, 2017.

[35] A. H. Monahan, “The probability distribution of sea surface wind speeds. Part I: Theory and seawinds observations," J. Climate, vol. 19, no. 4, pp. 497-520, 2006.

[36] X.-M. Li and S. Leher, “Algorithm for sea surface wind retrieval from TerraSAR-X and TanDEMX data," IEEE Trans. Geosci. Remote Sens., vol. 52, no. 5, pp. 2928-2939, 2014.

[37] M. B. Rivas, A. Stoffelen, J. Verspeek, A. Verhoef, X. Neyt, and C. Anderson, "Cone metrics: A new tool for the intercomparison of scatterometer records," IEEE J. Sel. Topics. Appl. Earth. Observ. Remote Sens., vol. 10, pp. 2195-2204, 2017. 
[38] Martyn, P., J. Williams, J. Nicoll, R. Guritz, and T. Bicknell, Calibration of the RADARSAT SWB processor at the Alaska SAR facility, paper presented at IEEE International Geoscience and Remote Sensing Symposium (IGARSS'99), Inst. of Electr. And Electr. Eng., Hamburg, Germany, 1999.

[39] Stern, H. L., and R. E. Moritz, "Sea ice kinematics and surface properties from RADARSAT synthetic aperture radar during the SHEBA drift," J. Geophys. Res., 107(C10), 8028, doi:10.1029/2000JC000472, 2002.

[40] A. P. Luscombe, "RADARSAT-2 SAR image quality and calibration operations," Can. J. Remote Sensing., vol. 30, pp. 345-354, 2004.

[41] J. Horstmann, W. Koch, S. Lehner, and R. Tonboe, "Wind retrieval over the ocean using synthetic aperture radar with C-band HH polarization," IEEE Trans. Geosci. Remote Sens., vol. 38, pp. 2122$2131,2000$.

[42] M. Portabella, A. Stoffelen, J. A. Johannessen, "Toward an optimal inversion method for synthetic aperture radar wind retrieval," J. Geophys. Res., vol. 107, no. C7, doi:10.1029/2001JC000925, 2002.

[43] F. Dobson, W. Perrie, B. Toulany, "On the deep-water fetch laws for wind-generated surface gravity waves," Atmosphere-Ocean, vo. 27, pp. 210-236, 1989.

[44] W. Perrie and B. Toulany, "Fetch relations for wind-generated waves as a function of wind-stress scaling," J. Phys. Oceanogr., vol. 20, pp. 1666-1681, 1990.

[45] A. Stoffelen, J. A. Verspeek, J. Vogelzang, and A. Verhoef, "The CMOD7 geophysical model function for ASCAT and ERS wind retrievals," IEEE J. Sel. Topics. Appl. Earth. Observ. Remote Sens., vol. 10, no. 5, pp. 2123-2134, 2017. 


\section{Figure and Table Captions}

Fig. 1. (Left) Histogram of collocated buoy wind speed (using a bin size of $2 \mathrm{~m} / \mathrm{s}$ ). (Right) Wind direction relative to SAR observation angle (using a bin size of $20^{\circ}$ ).

Fig. 2. (a) A C-band VV-polarized RADARSAT-2 SAR image, acquired with the fine quadpolarization mode on May 24, 2012, at 13:53 UTC (grayscale colorbar denotes $\sigma_{0}$, in units of decibels). The location of NDBC buoy \#46047 is indicated by the red plus (+). (b) NRCS scan inserted in the Fig. 2(a) versus incidence angle. (c) Time series of wind speeds measured by buoy \#46047 in one hour. RADARSAT-2 data are a product of MacDonald, Dettwiler, and Associates Ltd. All rights reserved.

Fig. 3. SAR-retrieved wind speeds from (a) CMOD4, (b) CMOD5, (c) CMOD5.N, (d) CMOD_IFR2, (e) C_SARMOD, and (f) C_SARMOD2. The color bar denotes wind speed (m/s). The location of the buoy is indicated by the red plus (+).

Fig. 4. A C-band VV-polarized RADARSAT-2 SAR image acquired with the dual-polarization mode onJanuary 3, 2010, at 22:20:50 UTC (grayscale colorbar denotes $\sigma_{0}$, in unit of decibels). Five NDBC buoys (\#44005, \#44032, \#44034, \#44027, and \#44037) off the east coast of the USA are labeled and indicated by red pluses (+). RADARSAT-2 data are a product of MacDonald, Dettwiler, and Associates Ltd., All rights reserved.

Fig. 5. SAR-retrieved wind speeds from (a) CMOD4, (b) CMOD5, (c) CMOD5.N, (d) CMOD_IFR2, (e) C_SARMOD, and (f) C_SARMOD2. The color bar denotes wind speed (m/s). The location of the buoys are indicated by the red pluses (+).

Fig. 6. Comparisons of SAR-retrieved wind speeds and in situ buoy wind speeds using six different GMFs: (a) CMOD4, (b) CMOD5, (c) CMOD5.N, (d)CMOD_IFR2, (e) C_SARMOD, and (f) C_SARMOD2.

Fig. 7. Computed error of wind speed due to an uncertainty in NRCS of $\pm 0.5 \mathrm{~dB}$ for incidence angles of $25^{\circ}$ (left), $35^{\circ}$ (middle), and $45^{\circ}$ (right). The error was computed for wind speeds between $3 \mathrm{~m} / \mathrm{s}$ and $20 \mathrm{~m} / \mathrm{s}$ and wind directions from $0^{\circ}$ to $180^{\circ}$. 
Fig. 8. The wind speed errors (Bias and Rmse) between CMOD5.N and C_SARMOD2 retrievals and buoy measurements versus different wind speed bins $(3-5 \mathrm{~m} / \mathrm{s}, 5-10 \mathrm{~m} / \mathrm{s}, 10-15 \mathrm{~m} / \mathrm{s}, 15-20 \mathrm{~m} / \mathrm{s})$ and radar incidence angle bins $\left(19-23^{\circ}(\mathrm{a}), 24-28^{\circ}(\mathrm{b}), 29-33^{\circ}(\mathrm{c}), 34-38^{\circ}(\mathrm{d}), 39-43^{\circ}(\mathrm{e}), 44-49^{\circ}(\mathrm{f})\right)$.

Fig. 9. Comparisons of SAR-retrieved wind speeds and in situ buoy wind speeds using CMOD7.

Table I. Major parameters of the RADARSAT-2 quad- and dual-polarization measurement modes.

Table II. Major parameters of the Sentinel-1AInterferometric Wide Swath (IW) measurement mode.

Table III. Results of wind speed retrievals by different GMFs and in situ observations from six buoys. 
Table I. Major parameters of the RADARSAT-2 quad- and dual-polarization measurement modes.

\begin{tabular}{lcc}
\hline Parameter & quad-polarization mode & $\begin{array}{r}\text { dual-polarization } \\
\text { ScanSAR Narrow mode }\end{array}$ \\
\hline Polarization & $\mathrm{HH}+\mathrm{HV}+\mathrm{VH}+\mathrm{VV}$ & $\mathrm{VV}+\mathrm{VH}$ \\
Incidence angles & $20^{\circ}-49^{\circ}$ & $20^{\circ}-46^{\circ}$ \\
Azimuth resolution & $8 \mathrm{~m}$ & $60 \mathrm{~m}$ \\
Range resolution & $5.4 \mathrm{~m}$ & $79.9-37.7 \mathrm{~m}$ \\
Swath & $25 \mathrm{~km}$ & $300 \mathrm{~km}$ \\
NESZ & $-36.5 \pm 3 \mathrm{~dB}$ & $28.5 \pm 2.5 \mathrm{~dB}$ \\
\hline
\end{tabular}

Table II. Major parameters of the Sentinel-1AInterferometric Wide Swath (IW) measurement mode.

\begin{tabular}{lc}
\hline Parameter & Interferometric Wide Swath (IW) mode \\
\hline Polarization & $\mathrm{VV}+\mathrm{VH}, \mathrm{HH}+\mathrm{HV}$ \\
Incidence angles & $31^{\circ}-46^{\circ}$ \\
Azimuth resolution & $20 \mathrm{~m}$ \\
Range resolution & $5 \mathrm{~m}$ \\
Swath & $250 \mathrm{~km}$ \\
NESZ & $-22 \mathrm{~dB}$ \\
\hline
\end{tabular}

Table III. Results of wind speed retrievals by different GMFs and in situ observations from six buoys.

\begin{tabular}{c|ccccccc}
\hline \hline $\begin{array}{c}\text { Buoy } \\
\text { ID }\end{array}$ & $\begin{array}{c}\text { Buoy } \\
\text { observations }\end{array}$ & $\begin{array}{c}\text { CMOD4 } \\
\text { retrievals }\end{array}$ & $\begin{array}{c}\text { CMOD5 } \\
\text { retrievals }\end{array}$ & $\begin{array}{c}\text { CMOD5.N } \\
\text { retrievals }\end{array}$ & $\begin{array}{c}\text { CMOD_IFR2 } \\
\text { retrievals }\end{array}$ & $\begin{array}{c}\text { C_SARMOD } \\
\text { retrievals }\end{array}$ & $\begin{array}{c}\text { C_SARMOD2 } \\
\text { retrievals }\end{array}$ \\
\hline 46047 & 12.80 & 10.00 & 11.00 & 11.50 & 11.00 & 11.00 & 12.50 \\
\hline 44005 & 13.87 & 11.50 & 13.50 & 14.00 & 13.00 & 12.50 & 13.50 \\
\hline 44027 & 14.70 & 11.50 & 12.00 & 12.50 & 11.50 & 12.00 & 13.00 \\
\hline 44032 & 11.99 & 8.00 & 9.00 & 10.00 & 9.50 & 8.50 & 10.00 \\
\hline 44034 & 14.17 & 11.00 & 11.50 & 12.00 & 11.00 & 11.50 & 12.00 \\
\hline 44037 & 6.54 & 5.00 & 5.00 & 6.00 & 5.00 & 5.00 & 5.50 \\
\hline Bias & & 2.85 & 2.01 & 1.35 & 2.18 & 2.26 & 1.26 \\
\hline RMSE & & 2.95 & 2.20 & 1.61 & 2.34 & 2.38 & 1.46 \\
\hline \hline
\end{tabular}



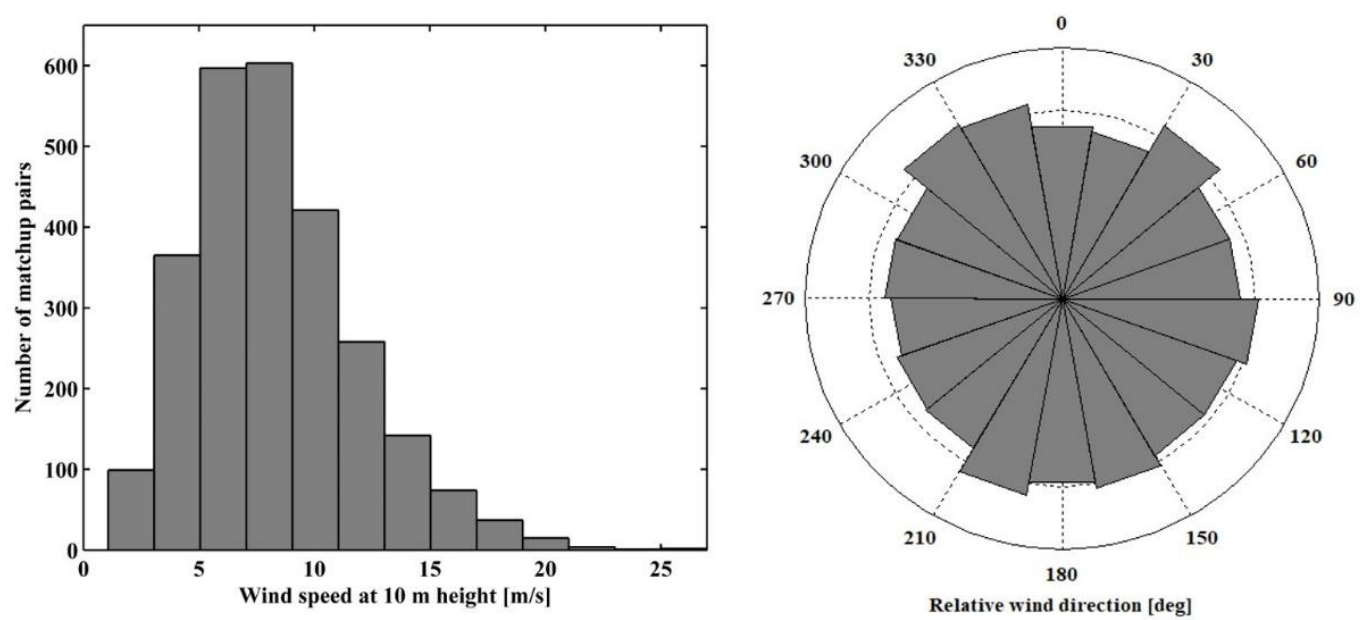

Fig. 1. (Left) Histogram of collocated buoy wind speed (using a bin size of $2 \mathrm{~m} / \mathrm{s}$ ). (Right) Wind direction relative to SAR observation angle (using a bin size of $20^{\circ}$ ). 

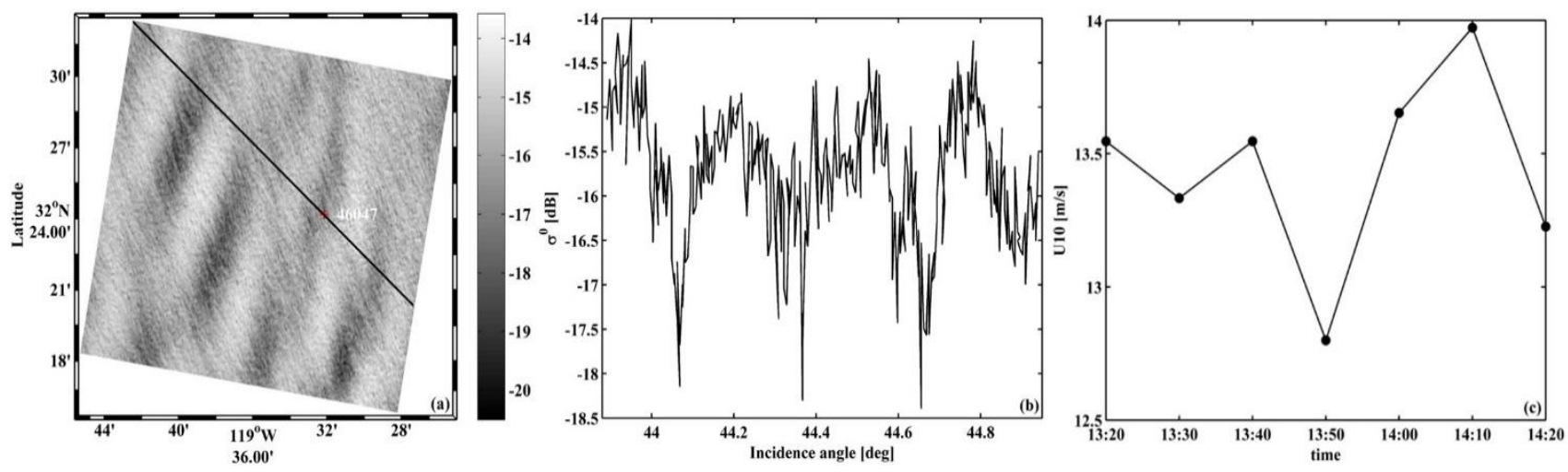

Fig. 2. (a) A C-band VV-polarized RADARSAT-2 SAR image, acquired with the fine quadpolarization mode on May 24, 2012, at 13:53 UTC (grayscale colorbar denotes $\sigma_{0}$, in units of decibels). The location of NDBC buoy \#46047 is indicated by the red plus (+). (b) NRCS scan inserted in the Fig. 2(a) versus incidence angle. (c) Time series of wind speeds measured by buoy \#46047 in one hour. RADARSAT-2 data are a product of MacDonald, Dettwiler, and Associates Ltd. All rights reserved. 

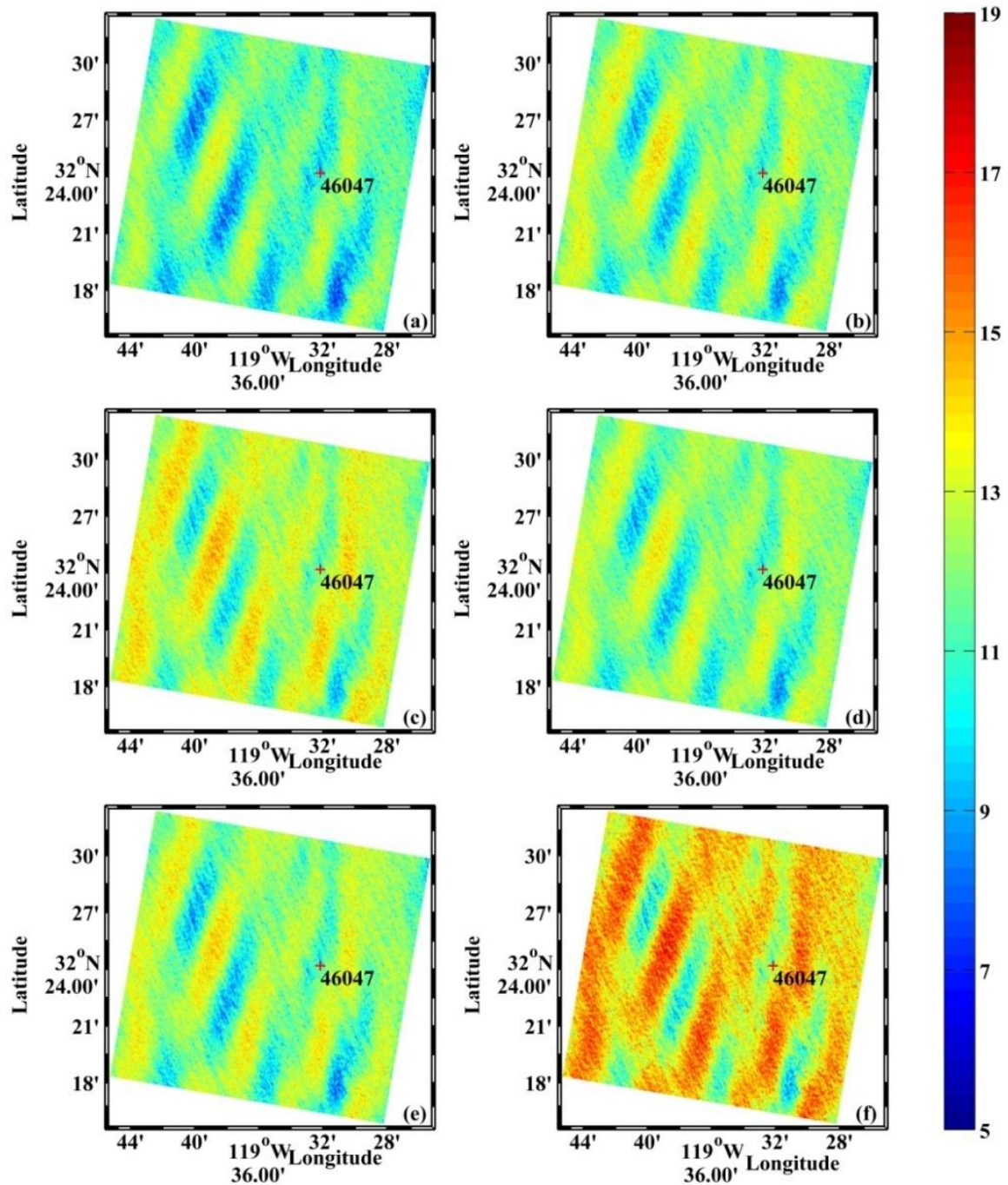

Fig. 3. SAR-retrieved wind speeds from (a) CMOD4, (b) CMOD5, (c) CMOD5.N, (d) CMOD_IFR2, (e) C_SARMOD, and (f) C_SARMOD2. The color bar denotes wind speed (m/s). The location of the buoy is indicated by the red plus (+). 


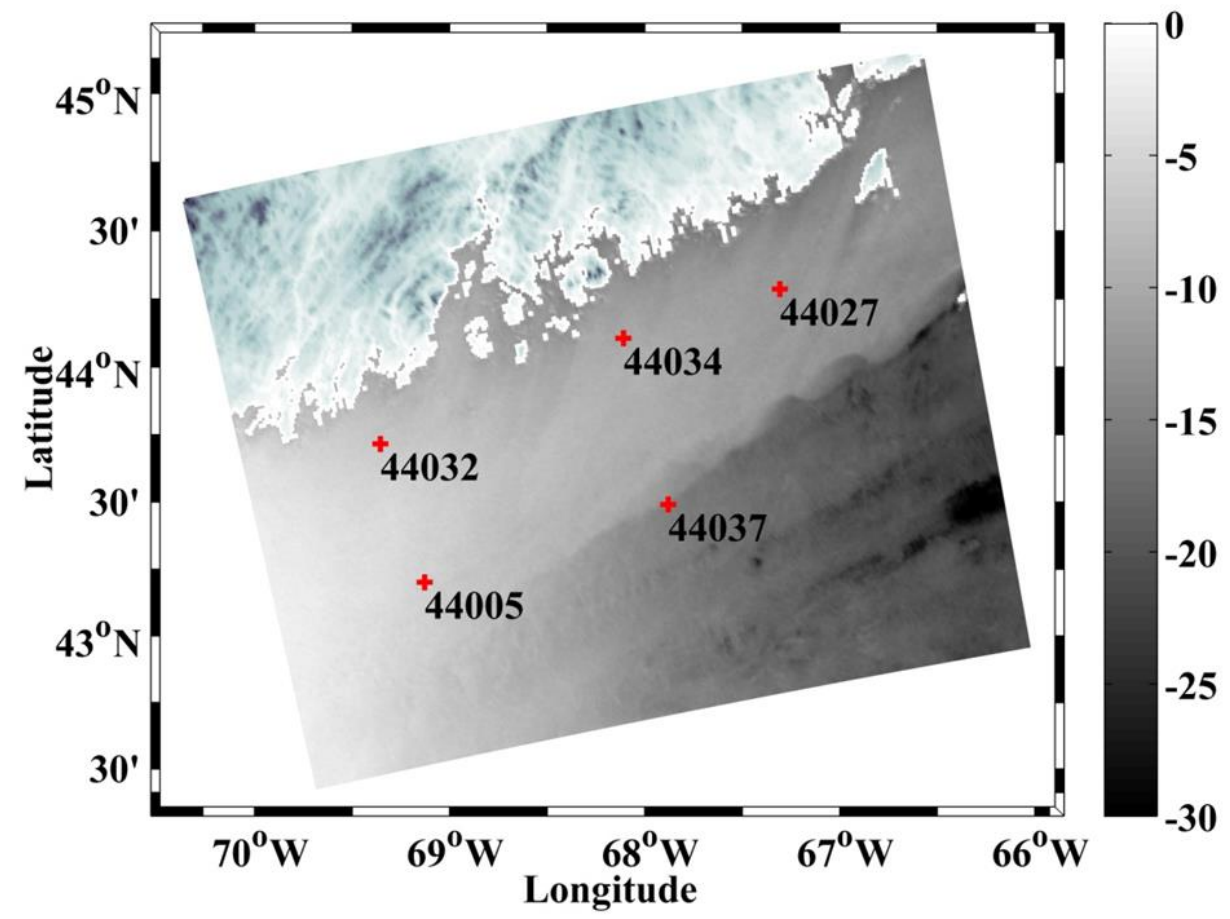

Fig. 4. A C-band VV-polarized RADARSAT-2 SAR image acquired with the dual-polarization mode on January 3, 2010, at 22:20:50 UTC (grayscale colorbar denotes $\sigma_{0}$, in unit of decibels). Five NDBC buoys (\#44005, \#44032, \#44034, \#44027, and \#44037) off the east coast of the USA are labeled and indicated by red pluses (+). RADARSAT-2 data are a product of MacDonald, Dettwiler, and Associates Ltd., All rights reserved. 

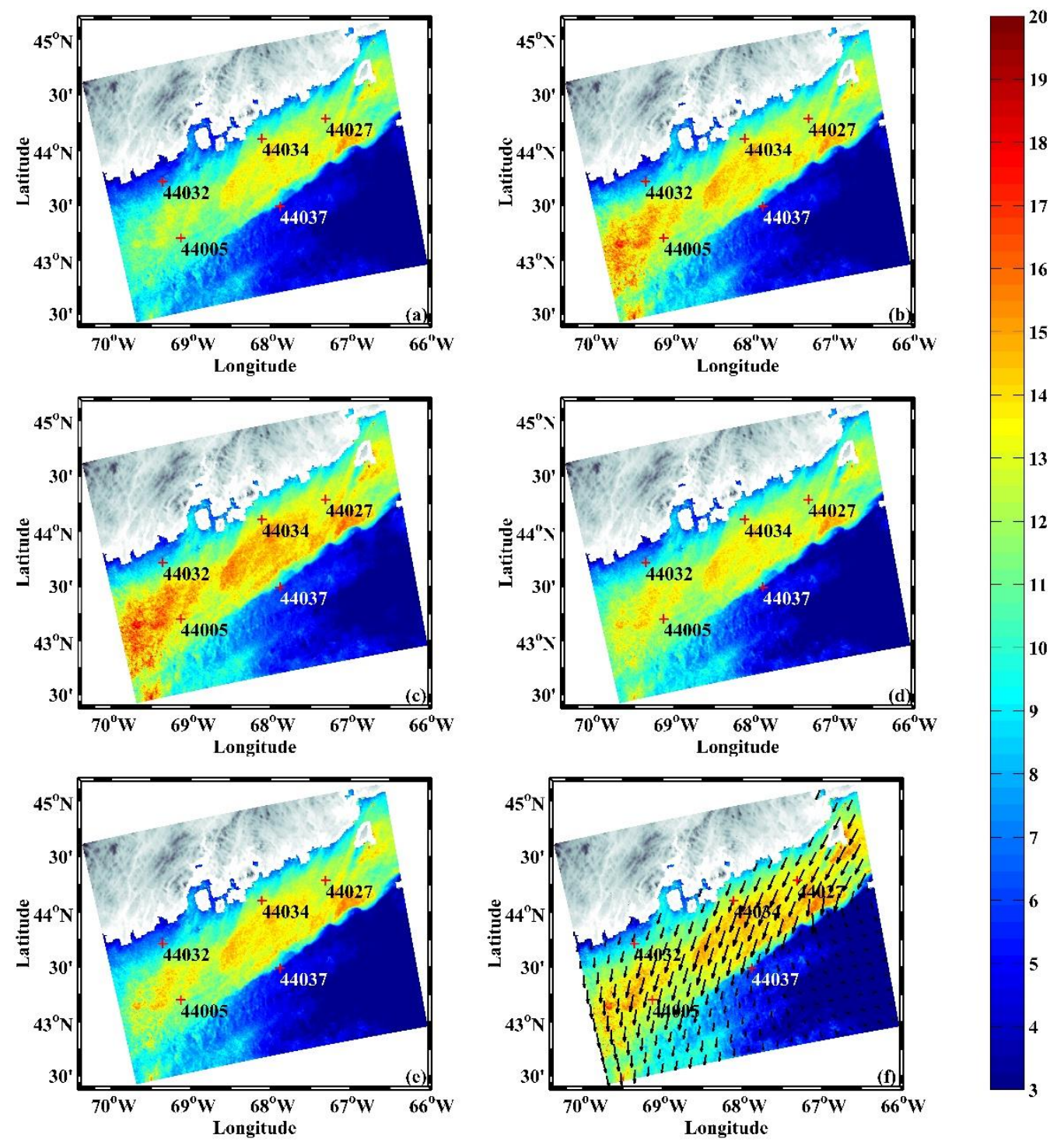

Fig. 5. SAR-retrieved wind speeds from (a) CMOD4, (b) CMOD5, (c) CMOD5.N, (d) CMOD_IFR2, (e) C_SARMOD, and (f) C_SARMOD2. The color bar denotes wind speed (m/s). The location of the buoys are indicated by the red pluses $(+)$. 

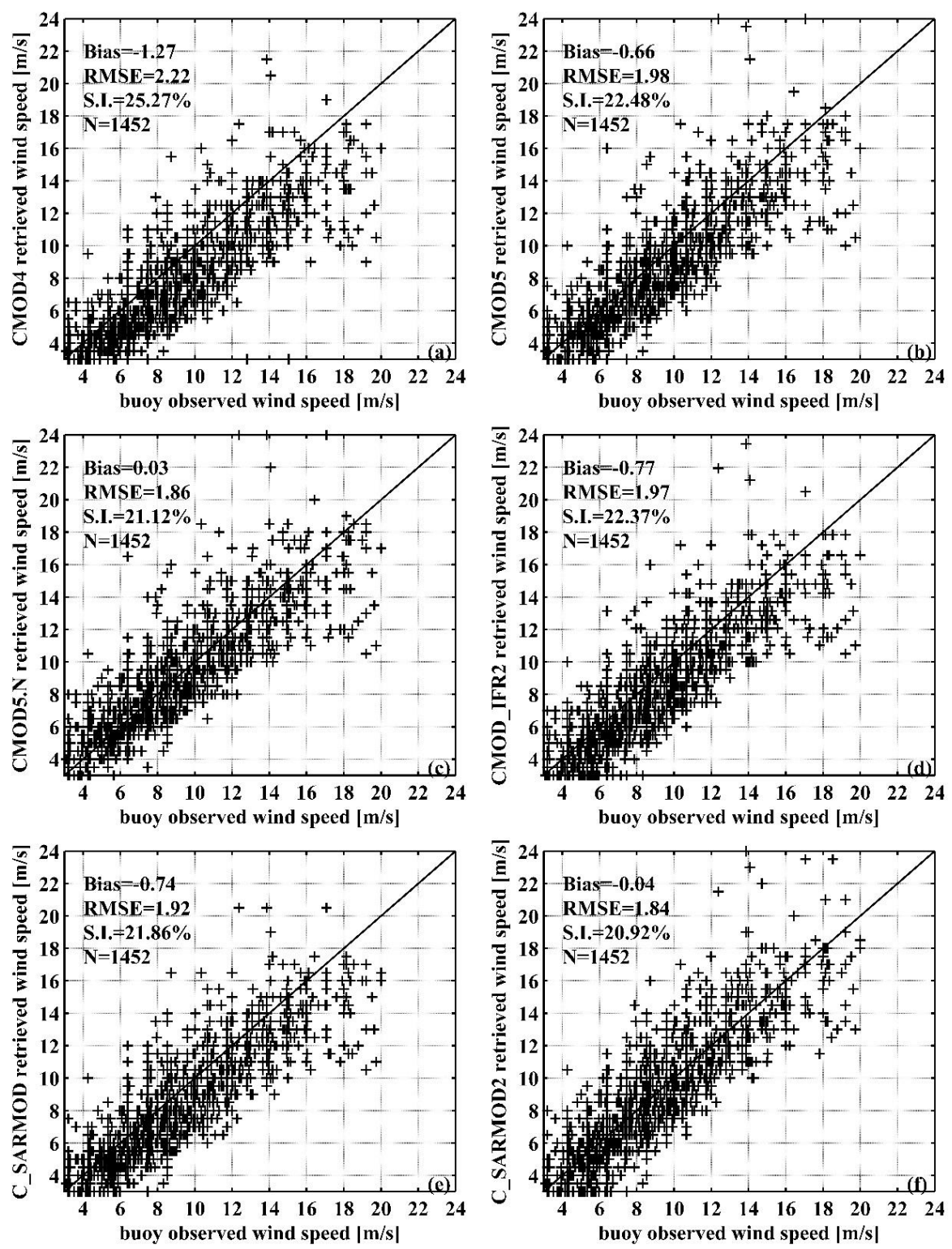

Fig. 6. Comparisons of SAR-retrieved wind speeds and in situ buoy wind speeds using six different GMFs: (a) CMOD4, (b) CMOD5, (c) CMOD5.N, (d) CMOD_IFR2, (e) C_SARMOD, and (f) C_SARMOD2. 

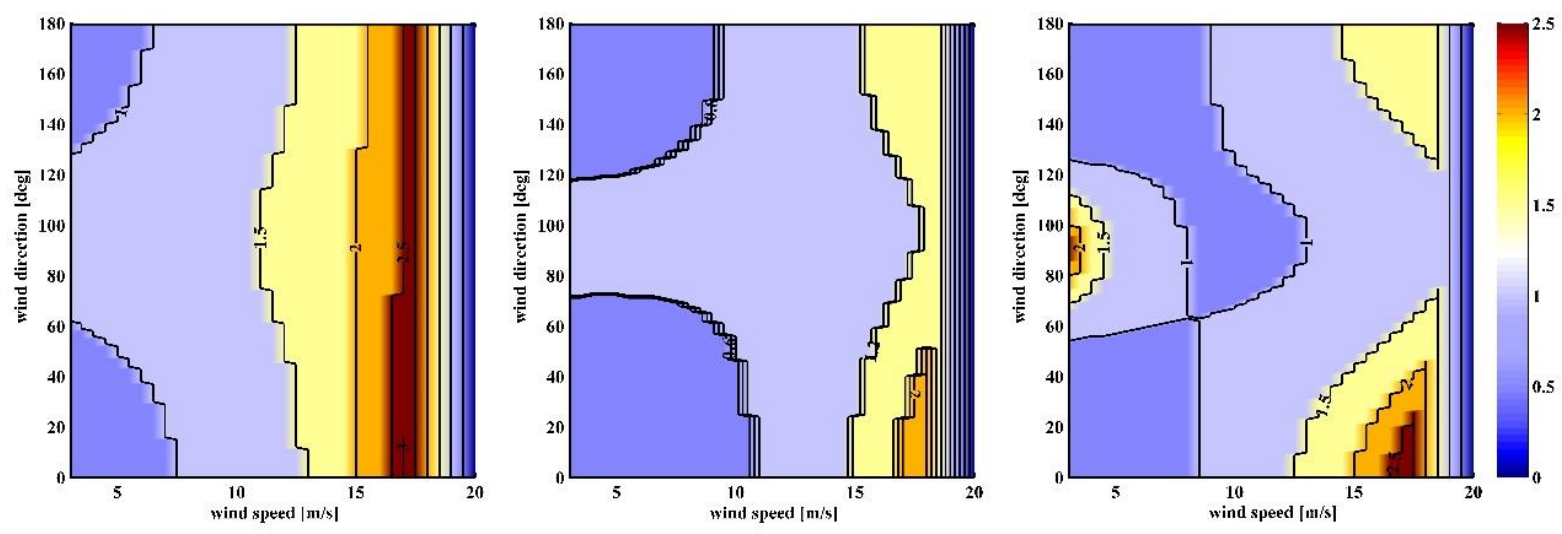

Fig. 7. Computed error of wind speed due to an uncertainty in NRCS of $\pm 0.5 \mathrm{~dB}$ for incidence angles of $25^{\circ}$ (left), $35^{\circ}$ (middle), and $45^{\circ}$ (right). The error was computed for wind speeds between $3 \mathrm{~m} / \mathrm{s}$ and $20 \mathrm{~m} / \mathrm{s}$ and wind directions from $25^{\circ}$ to $180^{\circ}$. 

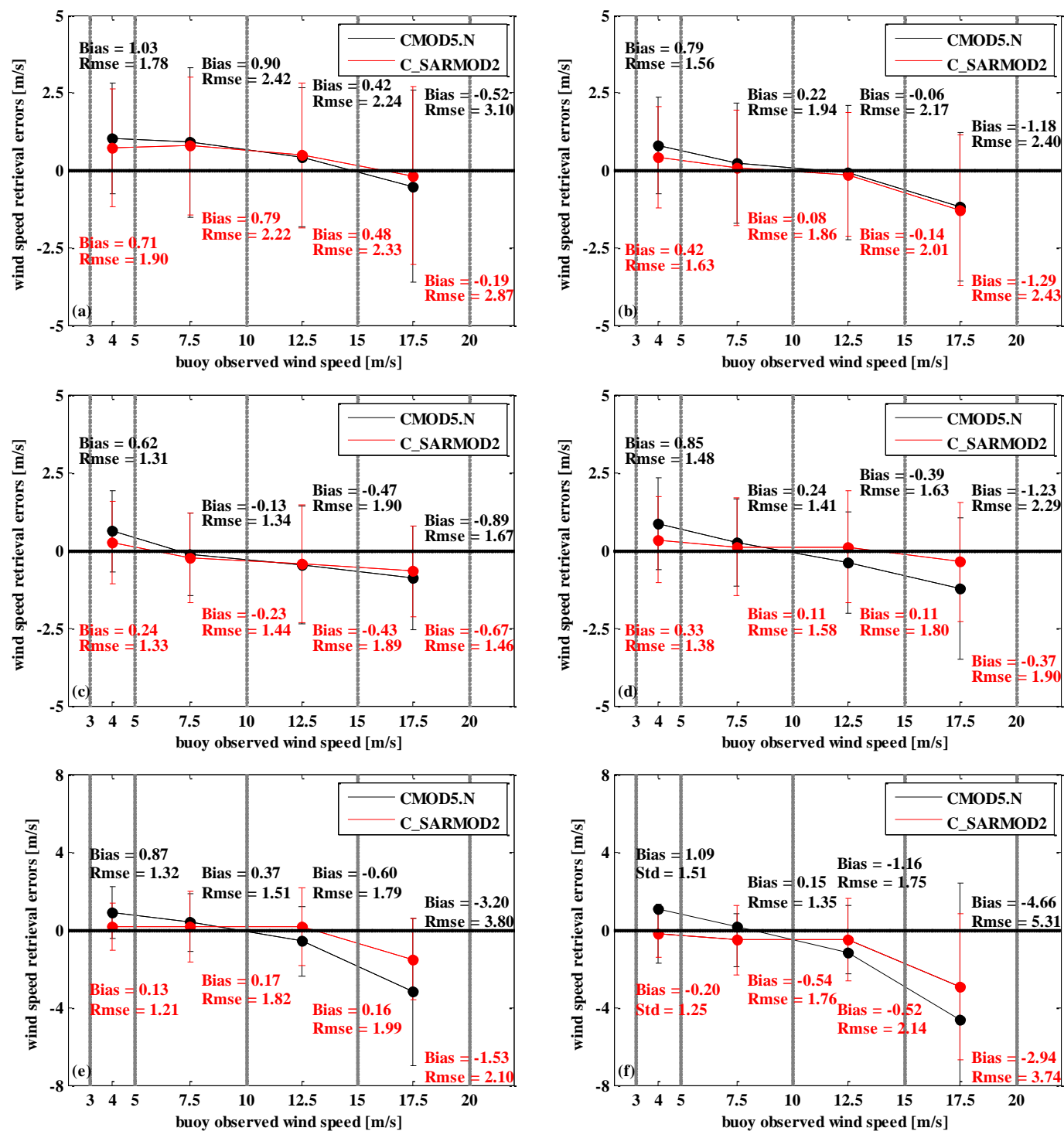

Fig. 8. The wind speed errors (Bias and Rmse) between CMOD5.N and C_SARMOD2 retrievals and buoy measurements versus different wind speed bins $(3-5 \mathrm{~m} / \mathrm{s}, 5-10 \mathrm{~m} / \mathrm{s}, 10-15 \mathrm{~m} / \mathrm{s}, 15-20 \mathrm{~m} / \mathrm{s})$ and radar incidence angle bins $\left(19-23^{\circ}(\mathrm{a}), 24-28^{\circ}(\mathrm{b}), 29-33^{\circ}(\mathrm{c}), 34-38^{\circ}(\mathrm{d}), 39-43^{\circ}(\mathrm{e}), 44-49^{\circ}(\mathrm{f})\right)$. 


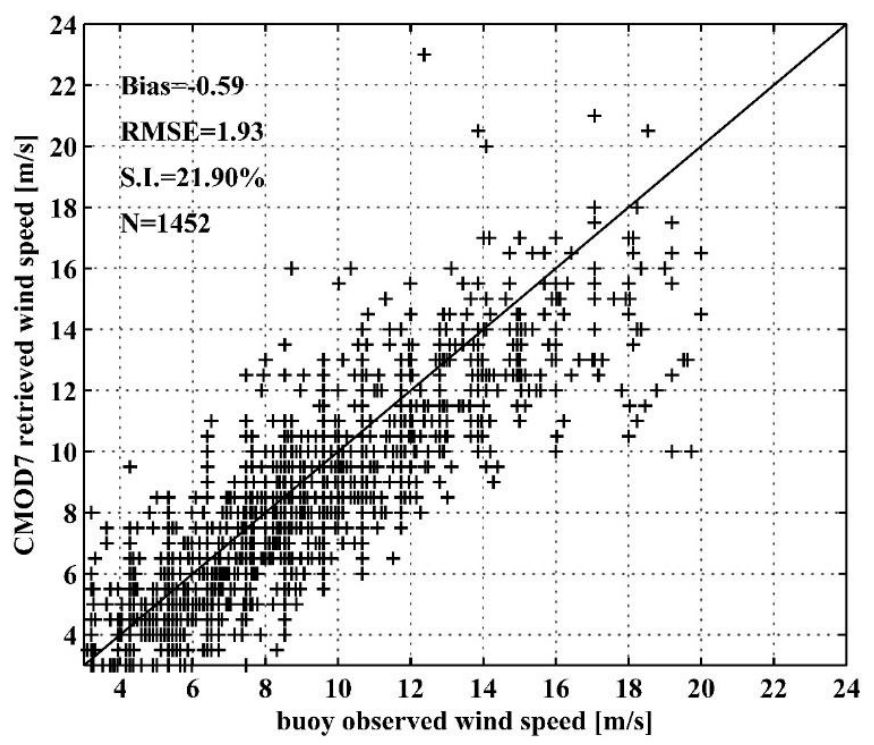

Fig. 9. Comparisons of SAR-retrieved wind speeds and in situ buoy wind speeds using CMOD7. 